\title{
The Pragmatics in Cross-Cultural Communication
}

\author{
PENG, XIAMEI \\ English Department, School of Foreign Languages \\ North China Electric Power University \\ Beijing, China \\ pengxiamei@139.com
}

\begin{abstract}
Cross-cultural communication is an inseparable part of linguistic theory and application. The present paper discusses cross-cultural communication from a pragmatics perspective. The first section of this paper is a brief introduction to the study of cross-cultural communication. Differences between communicators that come from different cultural background and cultural norms often give rise to misunderstanding. In section two of this paper, I illustrate eight aspects of differences on which cross-cultural communic ation can falter: talk or silence; what to say; pacing and pausing; listenership; intonation; indirectness; cohesion and coherence; and compliment responses in politeness. From these eight aspects, we can have a better understanding of what is meant by what is said and how communicative failure rises. The last section of the paper makes a summary to the issues discussed preceding it.
\end{abstract}

Keywords-linguistic, pragmatics, listenership, cohesion and coherence, cultural norms

\section{INTRODUCTION}

The study of cross-cultural communication is a paradigm example of the inseparability of linguistic theory and application. Linguists study cross-cultural communication for its applied significance, which is enormous, given the variety of societies affected by global migrations and the increasingly cross-cultural nature of commerce, diplomacy, and personal relationships throughout the world. And cross-cultural communication is also studied because "it provides a discourse analog to the starred sentence in linguistic argumentation". [1] By examining interactions in which habits and expectations about how to show what is meant by what is said are not shared, semantic processes-how language means — can be seen, which are harder to observe in the surface of successful communication.

In this paper I will illustrate the range of aspects of communication that can vary from culture to culture by discussing and exemplifying eight aspects of differences in signaling how speakers mean what they say. The nature of language is understood by observing it in communication and in contact with other systems of communication. Analyzing the pragmatics of cross-cultural communication is to analyze language itself.

\section{Aspects of Communication Differences}

\section{A. What to Say}

Once a speaker decides to talk, what is it appropriate to say? Can one ask questions, and what can one ask them about? It is reported that Australian Aborigines never ask the question "why" and similarly, Alaskan Athabaskans rarely ask questions. For these and other speakers, questions are regarded as too powerful to use, because they demand a response.

Many of us take it for granted that questions are basic to the educational setting. Goody (1978) found, however, that in a learning situation in Gonja, no questions were ever asked. As she puts it, Gonjan are so aware of the indirect function of questions to imply unstated meaning that "the pure information question hasn't got a chance[2]”.

A universal way of communicating is telling stories. But when are they told? How many can be told? What can they be about? What can the point be, and how is the point communicated?

It is found that New Yorkers of Jewish background were more likely than their California friends to tell stories, and their stories were more likely to be about their personal experience. The non-Jewish Californians in the conversation tended to talk about events that happened to them, without focusing on how they felt about those events. Members of each group after responded to the stories told by members of the other group with subtle signs of impatience or incomprehension like "Yeah, and?" or "what does it mean?" Stories are just one of a range of conversational acts which seem obviously appropriate when they are uttered, but may not seem appropriate to those whom they are uttered to-especially if the speaker and the hearer have different cultural backgrounds. For example, when and how and about what can jokes or stories be told? When is it appropriate to use irony and sarcasm, and how are they signaled? When can advice or information be offered-and how? How and when are compliments given and taken? A general principle is to be cooperative and void imposition.

Let's take the following case for example. The two persons concerned here, one is an American woman, while the other a Greek man. The American woman was invited to join a dinner party at the home of the man who was an excellent cook. He had prepared an elaborate dinner. During dinner, the American complimented the food: "These are delicious." The host 
agreed: "Yes, they are delicious." The American guest praised: "It must have taken hours to prepare." "Oh, yes," the host agreed. "These take many hours to prepare." Taking for granted that a host should not compliment his or her own cooking and should minimize his or her effort, the American decided that the host was egotistical. When leaving the dinner party, the American guest said, "Thank you for the wonderful meal." And the host retorted, "What, those little nothing?" with a dismissing wave of his hand in the direction of the table and a self-deprecating grimace on his face. The American was of course surprised again, and even felt hurt, as if he were implying she had been making too big a deal about the effort involved in preparing the meal. The American must have expected the host to accept the compliment this time, saying something like, "The pleasure was mine; come again."

So in this story the two people differ not about whether compliments should be accepted or deflected, but rather which compliment should be accepted and which deflected-and how. The cause of these differences is their different cultural conventions not personality characteristics. In cross-cultural communication, it is difficult to assess personality characteristics, because such judgments are always measured against cultural standards. If we don't know the standard, we can't "gauge the divergence from it", [3] as Sapir (1958) observed in discussing the intriguing question of the relationship between culture and personality. [4]

Inevitably, due to the misinterpretation of different cultural conventions, communicators may misunderstand each other, which is called sociopragmatic failure. See the following instance. An American invited a Chinese visiting-scholar to go to the movie. Below is the conversation between them:

American: What kind of movie do you prefer?

Chinese: I don't care. It's up to you.

American: Since I live here, I can go to any movie I like at any time. But if you have any movie particular in your mind, I will take you to that.

Chinese: I don’t mind. Any movie you like will be fine.

(Quoted from Xia, Jimei:1995)[5]

This is a typical example of sociopragmatic failure. The Chinese scholar takes it for granted that when being invited, the guest should confirm to the host's/hostess' arrangement to avoid imposition. But it is not the case with Americans. What the Chinese scholar should do is to "Do as the Romans do", i.e., express frankly to the American his own desire. For to the American, what the expected reply goes like these, " I think I would like to see an action movie/ a cartoon movie/ a movie starred by Tom Hanks" or " I have no idea, can you give me some suggestions?/ What would you suggest?/ Any good suggestions?”

\section{B. Listenership}

In conversation processing, showing listenership is also automatic and taken for granted. One way of doing this is through gaze. It was found that white participants in counseling interviews maintained eye gaze when listening and frequently broke their gaze when speaking. Black in the study did the opposite. They maintained steady eye contact when speaking and frequently broke their gaze when listening. This meant that when a white speaker talked to a black listener, he or she got the feeling that the listener wasn't paying attention because the expected sign of attention-steady gaze-wasn't there. And when the white speaker sent a small signal asking for confirmation of comprehension, the black listener often missed it because he or she was looking away. So the speaker said the same thing again, in simpler terms - talking down. But the when white was the listener, the black speaker's steady gaze seemed overbearing.

Similarly, this kind of listenership showing differences also happened between New Yorkers and Californians. In a study, it was discovered that New Yorkers had an enthusiastic way of showing listenership_-for example, shouting "Wow!" or "No kidding!" This was understood as a sign of attention and encouragement by speakers who shared the style. But such loud responses frightened and confused the Californianssometimes to the point of stopping them in their course of speaking.

If one's speaking habits create a strange reaction in a listener, rarely realizes that the strange behavior is a reaction to one's own way of talking. One thinks, instead, that the other has strange speaking habits-or is a strange person. For instance, the New Yorkers might never suspect why the Californians stopped. All they could see was that they kept hesitating and not getting on with their talk. And, on the other hand, the Californians might never suspect that the New Yorkers were simply being appreciative listeners. In this sense, misunderstanding would inevitably come out, but unfortunately, both parties concerned never realized it. Therefore, it is crucially important to show appropriately your listenerships when coming across different people of different styles.

\section{Intonation}

Intonation here is defined as a rising or following tone in a word, expression or sentence. Let's see the following example. In London's Heathrow Airport, airport staff who ate in the employees' cafeteria complained about rudeness by cafeteria employees from India and Pakistan who had been hired for jobs traditionally held by British women. And the Asian women complained of discrimination. It was rather hard to decide which side is more truthful, so a tape recorder was used to tape talk on the job to see what was going on, and had Asian and British employees listen to the tape together.

When a customer coming through the cafeteria line requested meat, the server had to find out if he wanted gravy on it. The British women asked, "Gravy?" the Asian women also asked "Gravy". But instead of rising, their intonation fell at the end. To this, the Asian women puzzled why they were getting negative reactions, since they were saying the same thing as the British women. But the British women pointed out that although they were saying the same word, they weren't saying the same thing. "Gravy?"- with question intonationmeans "Would you like gravy?" The same word spoken with falling intonation seems to mean, "This is gravy. Take it or leave it”. 
Tiny differences in intonation and prosody can throw an interaction completely off without the speakers knowing what caused the problem. Intonation is made up of degrees and shifts in pitch, loudness, and rhythm which make up every utterance. There are cultural differences in how these little signals are used, both to do conversational business as usual, and also to express special meanings or emotions. When intonational business-as-usual is mistaken for emotional expression, the result is miscommunication. "As E.M. Foster put it in A Passage to India, a novel which brilliantly portrays the tragic consequences of cross-cultural communication, 'a pause in the wrong place, an intonation misunderstood, and a whole conversation went awry”'. [3]

Like the rising or falling intonation that can result in miscommunication, degrees of loudness can also bring about misunderstanding. For example, it is shown that speakers of British English use loudness only when they are angry, whereas speakers of Indian English use it to get the floor. So when an Indian speaker is trying to get the floor, the British speaker thinks he or she is getting angry-and so gets angry in response. The result, both agree, is a heated interchange, but each thinks the other introduced the emotional tone into the conversation.

\section{Indirectness}

Communication in any culture is a matter of indirectness. Only a part of meaning resides in the words spoken; the large part is communicated by hints, assumptions, and prior experience. Yet how to be indirect is culturally relative.

Americans as a group tend to ignore or even object to indirectness. They believe that people should say what they mean and should be accountable only for what they say I words. They tend to forget the importance of the interpersonal level of interaction and think that in some (if not most or even all) instances, only the "content" counts.

This is the value associated with "getting down to brass tacks" and "sticking to facts". These values are taken for granted in American business and education, and perhaps more generally by American men. But it gets American business in trouble when they try to ignore the small talk and get right down to business with, for example, Japanese, Arab, or Mediterranean counterparts, for these people, "small talk" is big and essential, making the foundation for any business dealings. Apart from business barriers caused by different opinions towards indirectness, even in a family, it may give rise to controversy. I once met an American couple. The husband came from the North, whereas the wife the South of America. The husband joked that her wife never spoke directly, but always beat about the bush. If the wife wanted the husband to close the window, she did not ask him to close it, instead she just said, "It's rather cold here." To this "complaint", the wife retorted, "You never know how impositive you are, for you only give orders!” From this story, something universal can be reflected. Non-Americans, and American women, more often realize that much of what is meant can't be said directly. This introduces the enormous problem, even within a culture, of figuring out what is meant that is not said.
In an article on Greek vs. American and male vs. female uses of indirectness by Tannen (1982), [6] he demonstrated the operation and benefits of indirectness with the following example. A Greek woman told her that when she asked her father (as a girl) or her husband (as an adult) whether or not she could go somewhere, he would never say no. If he said, "If you want, you can go." She knew he didn't want her to. If he really thought it was a good idea he would be enthusiastic: "Yes, of course. Go." She knew from the way he said yes whether he meant yes or no. For many Americans, they take it as hypocritical. Why didn't he say what he meant? Actually, he did say what he meant in a way she had no trouble understanding. But if a Greek-American cousin came to visit the family and asked her uncle if she could do something and he answered in a way his daughter always understood, the cousin would be likely to take his ambiguous response literally. Although they speak the same language-Greek - they would be victims of cross-cultural miscommunication.

Now that commerce with Japan is widespread, there are frequent reports of frustration by Americans because polite Japanese never say no. But one must understand whether or not they mean it even if they say yes. Since Americans don't know the system, they don't know how to understand their counterparts' response-though they sometimes realize that yes often means no.

\section{E. Compliment Responses in Politeness}

Compliments have been said to "grease the social wheels" and thus to serve as "social lubricants"[7]. In our everyday life, we occasionally give compliments to other and receive compliments form other. Since compliments have a lot to do with politeness, it is quite crucial, therefore, to know how to respond appropriately to compliments. According to $\mathrm{Gu}$ (1990) [8], politeness in Chinese culture (actually also other Asian cultures) is quite different with that in western culture. Chinese people tend to apply self-denigration maxim to their daily communication. This maxim consists of two clauses: (a) denigrate self and (b) elevate other. "The breach of clause (a), i.e. denigrate other, is perceived as being impolite or rude. The breach of clause (b), i.e. elevate self, is construed as being 'arrogant', 'boasting', or 'self-conceited'”[9]. It is natural that Chinese try to avoid breaching this maxim, so when this is reflected in compliment responses, misunderstanding arises. The following conversation provides some insight into this issue.

A: You know, there are many similarities between English and Chinese.

\section{B: Really? I didn't know that.}

A: For example, if you meet an American young woman and say: "You're so pretty," she will respond with two words.

$\mathrm{B}$ : What are they?

A: "Thank you".

B: How about Chinese?

A: If you say the same thing to a Chinese young woman, she will also respond with two words. 
B: “Thank you”?

A: No. "Buzz off”!

\section{From a Chinese talk show}

Another example also shows Chinese people's overmodesty, which unexpectedly gives rise to communication failure in cross-cultural setting. A Chinese student, who went to Britain for advanced research, once met his director of research in the department corridor. The director said to the student: "I've heard that you are working very hard." The student replied: “That's not really true.” Then the director said: "That's no good," and then walked away leaving the student alone, regretting for his inappropriate response to his director's compliment. He should have expressed appreciation to his director's comments rather than showing modesty, which is a typical Chinese response to compliments. And it may be difficult to change his director's opinion of him. This communication failure shows, to some degree, that the Chinese student was not accustomed to British way of responding to compliments. And this is not just due to language inadequacy but also because of cultural norms.

\section{The Pragmatics in Communication}

The paper has described eight aspects in cross-cultural communication which may lead to misunderstanding between both parties concerned: talk or silence; what to say; pacing and pausing; listenership; intonation; indirectness; cohesion and coherence; and compliment responses in politeness. This list also describes the ways that meaning is communicated in talk. Communication is, by its very nature, culturally relative. Ways of communicating meaning in talk are learned in the speech community, i.e. by talking to people with whom one identifies socially. As social networks are always local, not global, people in different communities have different ways of using linguistic means to communicative ends, and their ways of talking, like other cultural patterns, define them as a community. This illustrates Hall's (1959) [10]assertion that culture is communication. To the extent that no two people have exactly the same communicative background, all communication is cross-cultural, and understanding crosscultural communication is a means to understand language at the same time that it is a means to understand, and improve problems and tasks facing the world and the people in it, including the task of teaching and learning new languages. Furthermore, cross-cultural communication also offers us some insight into the ELT (English Language Teaching) in China-students should not be required only in their grammatical learning, but more importantly, should improve their pragmatic competence.

\section{REFERENCES}

[1] Tannen, Deborah, and Muriel Saville-Troike (eds.). In press, Perspectives on Silence. Norwood, NJ: Ablex.

[2] Goody, Esther, 1978. 'Toward a theory of question s' in Esther Goody (ed.). Questions and Politeness. Cambridge: Cambridge University Press.

[3] Tannen, Deborah, 1984. 'The pragmatics of cross-cultural communication'. Applied Linguistics 5: 189-195.

[4] Sapir, Edward, 1958. 'Speech as a personality trait' in David mandelbaum (ed.). Selected Writings of Edward Sapir in Language, Culture, and Personality. Berkeley: University of California Press.

[5] Xia, Jimei, Common Sense about Language Communication: Case Analysis of the Misunderstanding between Chinese and Foreigners. Guangzhou: Zhongshan University Press.

[6] Tannen, Deborah, 1982. 'Ethic style in male-female conversation' in John J. Gumperz (ed.). Language and Social Identity. Cambridge: Cambridge University Press.

[7] Wolfson, Nessa, 1983. 'An empirically based analysis of complimenting in English'. In: N. Wolfson and E. Judd (eds.), Sociolinguistics and Language Acquisition, 82-95. Rowley, MA: Newbury House.

[8] Gu, Yueguo, 1990. Politeness phenomena in modern Chinese. Journal of Pragmatics 14: 237-257.

[9] Thomas, J., 1983. 'Cross-cultural pragmatics failure'. Applied Linguistics 4 (3).

[10] Hall, Edward, 1959. The Silent Language. New York: Doubleday. 